\title{
ANÁLISE DOS MARCADORES DE RELAÇ̃̃o LÓGICA NO GÊNERO NOTÍCIA DE POPULARIZAÇÃo CIENTÍFICA PELA PERSPECTIVA DA GRAMÁTICA-SISTÊMICO FUNCIONAL
}

\author{
Desirée Mota-Roth - Prof ${ }^{\text {a }}$ do Programa de Pós-Graduação em Letras (UFSM) \\ Cristina dos Santos Lovato - Mestranda do Programa de Pós-Graduação em Letras (UFSM)
}

\begin{abstract}
RESUMO: O objetivo deste estudo é descrever a função e a freqüência dos elementos responsáveis pela coesão textual em termos de organização das relações lógico-semânticas em notícias de popularização científica (PC) em português. O ponto de partida para o estudo é a metafunção textual da gramática sistêmico funcional (HALLIDAY, 2004), especificamente o sistema de conjunções. São apresentados os resultados da análise de um corpus de 15 textos, extraídos da revista Ciência Hoje On-line, quanto à recorrência de conjunções. Primeiramente, foi feita uma análise quantitativa desses dispositivos coesivos para, posteriormente analisar a função desses elementos nos textos. Análises prévias sobre a organização retórica do gênero notícia de popularização da ciência (XXXXX, 2007; XXXXX, 2008) indicaram duas características centrais, polifonia e reelaboração. Os resultados obtidos na presente análise indicam a presença de três tipos de relações lógico-semânticas entre orações: extensão, elaboração, e intensidade, associadas aos fenômenos de polifonia e reformulação.
\end{abstract}

PALAVRAS-CHAVE: metafunção textual, sistema de conjunções, gênero notícia de popularização científica.

ABSTRACT: The objective of this study is to describe the function and the frequency of the elements responsible for textual cohesion in terms of logic-semantic relations in science popularization news (PC) in Portuguese. The starting point for this study is the textual metafunction of Systemic-Functional Grammar, specifically the system of conjunctions (HALLIDAY, 2004). The results of the analysis of 15 texts, extracted from Ciência Hoje On-Line are presented, considering the recurrence of conjunctions. Firstly a quantitative analysis of these cohesive devices was done in order to subsequently analyze the function of these elements in these texts. Previous analyses about the rhetorical organization of scientific popularization news genre (XXXXX, 2007; XXXXX, 2008) have indicated two central generic characteristics - polyphony and re-elaboration. The results obtained in the present analysis indicate the presence of three types of logic-semantic relations between sentences: extension, elaboration and enhancement, associated with polyphony and re-elaboration phenomena.

KEYWORDS: textual metafunction; system of conjunction; scientific popularization news genre.

\section{INTRODUÇÃO}

\section{Contextualização}

O presente trabalho integra o projeto de pesquisa coordenado pela primeira autora, intitulado XXXXXXXX (CNPq $\mathrm{n}^{\circ} \mathrm{XXXXX)}$ ), realizado no XXXX. Este trabalho tem por objetivo analisar a função e a freqüência dos elementos responsáveis pela coesão textual em termos de organização das relações lógico-semânticas em notícias de popularização da ciência em português.

Popularização da ciência, segundo definição de Mueller (2002 p. 1-2), é o processo de transposição das idéias contidas em textos científicos para os meios de comunicação populares, como jornais e revistas eletrônicas. Complementando essa conceituação, Casamiglia e Dijk (2004, p. 370) apontam que popularização da ciência é a transformação do conhecimento científico em conhecimento acessível a leitores não-especializados. Nessa perspectiva, a popularização da ciência por meio dos textos que reescrevem de forma simplificada a escritura científica possibilita a integração do conhecimento das ciências à vida cotidiana.

Pressupomos que o sistema de conjunções responsável pelas relações lógico-semânticas entre orações ajuda a realizar a função pedagógica das notícias de PC, pois sinaliza 
explicitamente as relações entre os conceitos científicos. No discurso científico (dirigido a especialistas), tais relações estão normalmente sinalizadas por coesão lexical (PAGANO, 1998, p.58), estabelecendo redes semânticas entre termos superordinados e seus hipônimos, por exemplo.

O ponto de partida para este estudo, portanto, está na metafunção textual da Gramática Sistêmico-Funcional de M. A. K. Halliday (1994; 2004), especificamente o sistema de conjunções responsável pelas relações lógico-semânticas entre orações. As conjunções, segundo Halliday (2004, p. 540), marcam as relações entre segmentos de texto, no sentido de que um segmento elabora, amplia ou realça o significado de outro que o precede ou segue.

Para descrever a incidência de conjunções em nosso corpus, na primeira parte deste trabalho, apresentamos um breve resgate teórico da perspectiva funcional da linguagem segundo Halliday (2004), sintetizando as três metafunções. Em seguida, conceituamos coesão textual e dispositivos de relações lógico-semânticas em orações. Por fim, apresentamos os resultados e a discussão dos dados.

\section{Gramática sistêmico-funcional}

A gramática sistêmico-funcional desenvolvida por Halliday $(1994,2004)$ tem suas bases na corrente funcionalista da linguagem, que considera a língua como um sistema maleável sujeita as pressões oriundas das diferentes situações comunicativas (CUNHA et all, 2003, p. 20-21).

Para Halliday (2004), são exatamente os usos que dão forma ao sistema lingüístico, isto é, a funcionalidade é inerente à língua (HALLIDAY, 2004, p. 30). Nesse sentido, a organização da língua não é arbitrária, ela se molda de acordo com as necessidades do falante na interação. Uma gramática funcional é essencialmente uma gramática "natural", no sentido de que tudo nela pode ser explicado, em última instância, com referência a como a língua é usada (NEVES, 2004, p.62).

A gramática da língua é representada por redes sistêmicas, derivadas das escolhas realizadas pelos usuários nas mais diversas situações comunicativas (HALLIDAY, 2004, p. 23). Essas diferentes redes sistêmicas codificam diferentes espécies de significado, ligando-se às três funções da linguagem ou "metafunções" (NEVES, 2004, p. 60). A metafunção ideacional da língua expressa conteúdos e experiências de mundo por meio do sistema de transitividade, das funções de cada elemento da léxico-gramática dentro da frase (HALLIDAY, 2004, p.29). A interpessoal expressa a capacidade da língua em estabelecer relações entre os participantes da interação (NEVES, 2004, p.65). Por meio dos sistemas de modo e modalidade, a identidade dos participantes é expressa e constituída. Por fim, a metafunção textual diz respeito à construção do texto como uma unidade semântica ordenada por meio dos processos de coesão e coerência e da estrutura temática. Essa função é responsável pela coesão entre as sentenças em um discurso (HALLIDAY, 2004, p. 30).

\subsection{O conceito de coesão}

Segundo Halliday e Hasan (1976, p. 195), o termo coesão é usado "para designar um conjunto de fenômenos da linguagem recuperáveis por marcas específicas, que permitem que as frases sejam ligadas para formar um texto". Assim, a coesão é um dos aspectos que constituem a "textualidade" do texto, referindo-se às relações de sentido que se estabelecem entre itens lexicais do texto. Essas relações permitem que a interpretação de um elemento dentro do texto dependa da interpretação de outro.

Halliday e Hasan (idem: ibidem) dividem a coesão em cinco categorias segundo o modo 
como os itens lexicais e gramaticais relacionam-se com o texto e no texto: referência, substituição, elipse, coesão lexical e conjunção.

\subsection{Relações lógico-semânticas entre orações: O sistema de conjunções}

As conjunções diferem dos outros dispositivos coesivos, pois não estabelecem apenas uma relação anafórica (HALLIDAY e HASAN, 1976, p. 226), não são empregadas para alcançar algo que a precede ou segue. São dispositivos coesivos em virtude de seus significados específicos que pressupõem a presença de outros componentes no discurso.

Resumidamente, Halliday (2004, p. 540-548) aponta três tipos de relações entre orações: "elaboração", "extensão" e "intensidade". Na elaboração, uma oração tem seu sentido elaborado por outra que a especifica ou descreve, reformulando-a ou exemplificando-a ("em outras palavras, "por exemplo,"). Na extensão, uma oração amplia o sentido de outra, acrescentando uma informação nova. Ocorre por adição ("e", "também", "além de", etc.), por relação de adversidade ("no entanto", "mas", "porém”, etc.) ou variação ("ou”, etc.). Na relação de intensidade, uma oração realça o significado de outra, qualificando-a em termos de referência ao tempo ou ao espaço ("aqui", "lá", "ao mesmo tempo"), modo ("assim", "semelhantemente"), causa-condição ("então", "se”) e questão ("a esse respeito", "em todos os outros casos") (HALLIDAY, 2004, p. 544-548).

Segundo Fairclough (2001, p. 218), as principais relações de intensidade entre orações e períodos são relações temporais (A então $B, A$ depois de $B, A$ quando $B, A$ enquanto B, etc.considerando-se A e B orações ou períodos); relações causais, tais como relações de razão ou propósito; relações condicionais (se A então B); relações espaciais (A onde B); e comparações (A como B, A da mesma forma B).

É preciso ressaltar, no entanto, que, muitas vezes, as relações entre orações não são explícitas, sinalizadas por conjunções (FAIRCLOUGH, 2004, p.89), principalmente quando apresentam uma relação de elaboração apositiva expositiva, em que o sentido de uma oração é reelaborado e explicado pela oração seguinte.

Essa reelaboração é sinalizada por um mecanismo de coesão como travessão, parênteses e aposto entre vírgulas. Diferentemente das relações de elaboração apositiva por exemplificação, quando a relação é explicitada pelo emprego de 'por exemplo' que sinaliza a relação entre uma classe e um membro.

\section{Metodologia}

O corpus deste estudo é composto por 15 textos com temas relacionados às ciências médicas, extraídos da revista eletrônica Ciência Hoje On-Line, publicados entre 2000 e 2008 . A análise foi dividida em três momentos, o primeiro foi dedicado à coleta, seleção e organização dos textos. A segunda parte se concentrou na análise quantitativa das conjunções por meio do levantamento e da contagem. Por fim, foi feita a análise qualitativa que objetivou verificar a função desses elementos nos textos de PC em Português.

Para fins de análise, optamos por considerar somente os dispositivos de relação lógicosemântica explícitos na superfície textual. Análises prévias sobre a organização retórica do gênero notícia de popularização da ciência (XXXXX, 2007; XXXXX, 2008) indicaram duas características marcantes no gênero, polifonia e relaboração. De fato, os resultados obtidos na presente análise indicaram a presença de três tipos de relações lógico-semânticas entre orações: extensão, elaboração, e intensidade, associadas aos fenômenos de polifonia e reformulações. 


\section{Resultados e Discussão}

\subsection{Análise quantitativa dos dados}

A análise quantitativa indicou que, nos 15 textos analisados, há 384 conjunções, distribuídas em três tipos de relações: "elaboração", "extensão" e "intensidade". As relações de extensão tiveram incidência de 164 vezes nos textos; as de elaboração, 121 vezes; e as de intensidade, 99 vezes.

As Tabelas 1, 2 e 3 apresentam respectivamente as conjunções de extensão, elaboração e intensidade, seus subtipos, exemplos retirados dos textos do corpus, quando houver, e total de ocorrência. A Tabela 1 apresenta o total de ocorrência das relações de extensão.

\section{Tabela 1 - Conjunções de extensão nos texto de PC em português}

\begin{tabular}{|c|c|c|c|c|}
\hline Tipos & \multicolumn{2}{|l|}{ Subtipos } & Exemplos & $\mathrm{N}$ \\
\hline \multirow{6}{*}{ Extensão } & \multirow[b]{2}{*}{ Aditiva } & Positiva & E, também, além de & 133 \\
\hline & & $\begin{array}{l}\text { Negativa } \\
\text { ("nem") }\end{array}$ & - & - \\
\hline & Adversativa & & $\begin{array}{l}\text { Mas, no entanto, por outro lado, } \\
\text { porém }\end{array}$ & 18 \\
\hline & \multirow[t]{3}{*}{ Variativa } & $\begin{array}{l}\text { Substitutiva } \\
\text { ("pelo contrário", “ao } \\
\text { invés de") }\end{array}$ & - & - \\
\hline & & $\begin{array}{l}\text { Subtrativa ("ademais } \\
\text { que", "exceto que") }\end{array}$ & - & - \\
\hline & & Alternativa & $\mathrm{Ou}$ & 11 \\
\hline & & & Total & 162 \\
\hline
\end{tabular}

As conjunções de extensão são predominantes nos textos há 148 ocorrências, conforme Tabela 1. Esse tipo de relação ocorre muito mais freqüentemente pelo emprego de conjunções aditivas (133 ocorrências) do que pelo emprego de conjunções adversativas (18 ocorrências) e variativas (11 coerências).

\section{Exemplo 1}

Pesquisadores brasileiros constataram que o material genético do parasita causador da doença de Chagas pode ser transferido para o genoma do hospedeiro. Os cientistas também descobriram que esse DNA do animal infectado integrado ao do Trypanosoma cruzi pode ser transmitido hereditariamente, ao menos em galinhas (MOEHLECKE, 2004).

\section{Exemplo 2}

A incorporação do kDNA em mamíferos e as mutações herdadas pelas aves geraram modificações no genoma dos hospedeiros... (idem).

\section{Exemplo 3}

Segundo Marcela Lopes, pesquisadora da UFRJ que coordena a pesquisa, o objetivo inicial não era desenvolver novas terapias, mas entender o papel do sistema imunológico no combate à infecção. (idem).

\section{Exemplo 4}

Foi constatado que o ácido acetilsalicílico é capaz de bloquear essas reações e, conseqüentemente, impedir a multiplicação do parasita. No entanto, os pesquisadores concordam que seria prematura a consagração da aspirina como cura para o mal de Chagas (CONSENDEY, 2000). 
Nos exemplos 1 e 2, as relações entre as orações são estabelecidas pelo emprego de conjunções de extensão aditivas positivas. Nos exemplos 3 e 4, as relações são estabelecidas pelo emprego de conjunções de extensão adversativas.

\section{Tabela 2 - Conjunções de elaboração nos textos de PC em português}

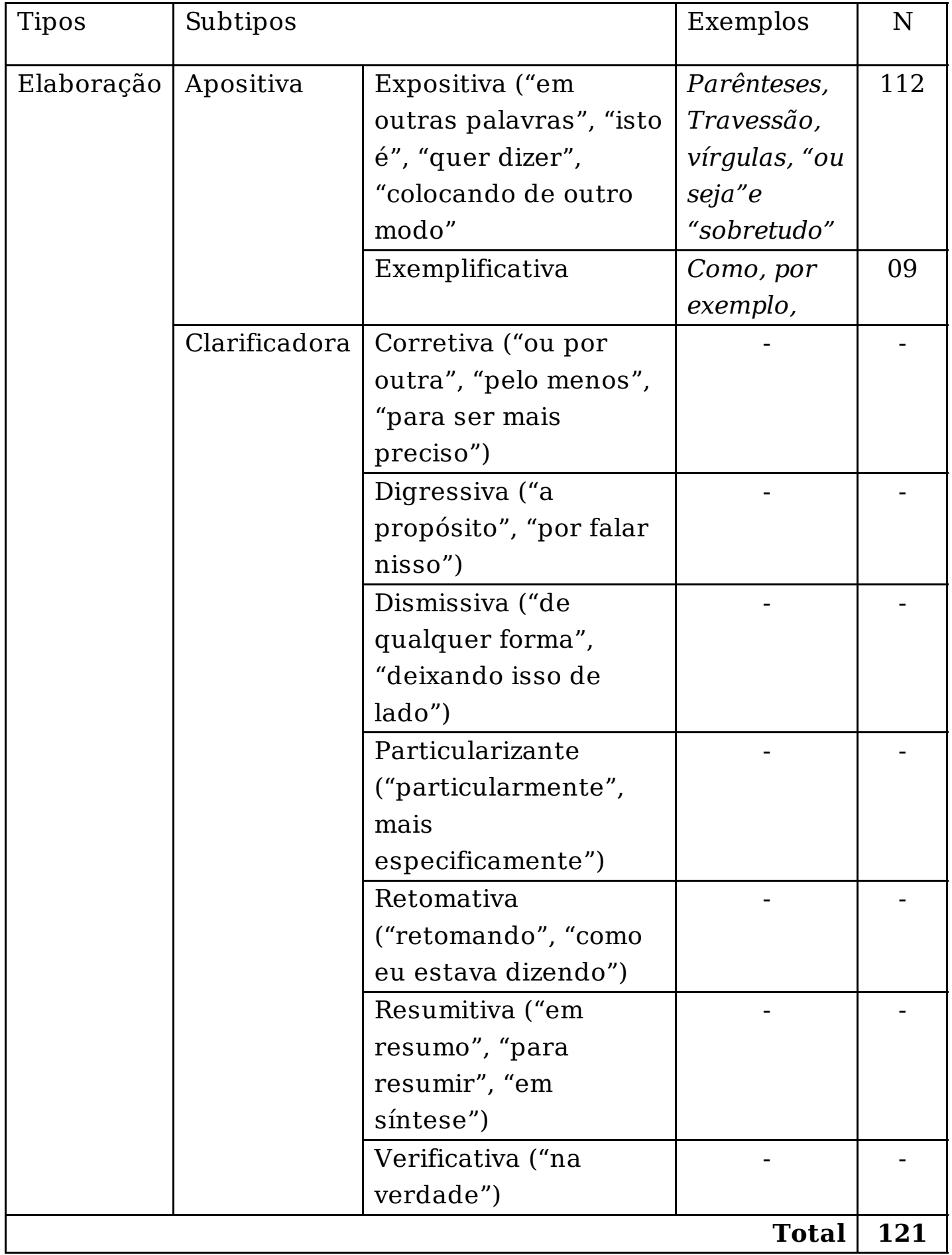

A Tabela 2 mostra as 121 ocorrências de conjunções de elaboração apositiva expositiva, na sua maioria (112) com função de explicar ou reformular a oração anterior. A elaboração ocorreu recorrentemente pelo emprego de parênteses, vírgulas e travessões, conforme exemplos extraídos de textos do corpus.

Exemplo 5

... $51 \%$ dos embriões abortados naturalmente apresentam falhas nos cromossomos - estruturas do núcleo celular formadas por uma molécula de DNA e proteínas (MARQUES, 2002).

Exemplo 6

O cariótipo (conjunto de cromossomos)... (idem). 


\section{Exemplo 7}

As alterações numéricas que acarretam abortos espontâneos ocorrem por acaso, ou seja, não estão associadas a distúrbios dos pais (idem).

\section{Exemplo 8}

Mas, além de usar a pomada, é preciso tomar outros cuidados, como fazer a assepsia local (WALTZ, 2008).

Nos exemplos 5 e 6, as reformulações ocorrem por elaboração apositiva expositiva expressa por símbolos gráficos. No primeiro exemplo, a explicação do termo "cromossomo" está entre travessões. No segundo exemplo, a especificação do termo "cariótipo" está entre parênteses. No exemplo 7, a elaboração é introduzida por uma conjunção ("ou seja”). Por fim, no exemplo 8, há uma relação de elaboração apositiva explicativa introduzida pelo dispositivo de relação lógico-semâtica "como".

As conjunções de intensidade não são muito recorrentes nos textos de PC nesta pesquisa, há um total de 98 conjunções, número inferior de ocorrência em relação às conjunções de elaboração, 121 ocorrências, e de extensão, 164 ocorrências.

Tabela 3- Conjunções de intensidade nos textos de PC em português

\begin{tabular}{|c|c|c|c|c|c|}
\hline Tipos & \multicolumn{3}{|l|}{ Subtipos } & Exemplos & $\mathrm{N}$ \\
\hline \multirow[t]{9}{*}{ Intensidade } & \multicolumn{3}{|c|}{$\begin{array}{l}\text { Questão (“a esse respeito", "em todos os } \\
\text { outros casos") }\end{array}$} & - & - \\
\hline & \multirow[t]{8}{*}{$\begin{array}{l}\text { Espaço- } \\
\text { temporal }\end{array}$} & \multirow[t]{3}{*}{ Simples } & Simultânea & $\begin{array}{l}\text { Em seguida, } \\
\text { então, primeiro, } \\
\text { segundo }\end{array}$ & 04 \\
\hline & & & Anterior & Antes & 01 \\
\hline & & & $\begin{array}{l}\text { Conclusiva } \\
\text { ("finalmente") }\end{array}$ & & \\
\hline & & \multirow[t]{5}{*}{ Complexa } & $\begin{array}{l}\text { Imediata } \\
\text { ("imediatamente, } \\
\text { "agora mesmo") }\end{array}$ & & \\
\hline & & & $\begin{array}{l}\text { Interruptiva } \\
\text { ("tão logo", } \\
\text { "assim que”) }\end{array}$ & - & - \\
\hline & & & $\begin{array}{l}\text { Repetitiva } \\
\text { (“da próxima } \\
\text { vez", “em outra } \\
\text { ocasião”), }\end{array}$ & - & - \\
\hline & & & Especificativa & $\begin{array}{l}\text { Após três dias, } \\
\text { cerca de um ano, } \\
\text { desder1995, em } \\
\text { 2000, desde 1996, } \\
\text { Entre } 1997 \text { e } 1999\end{array}$ & 24 \\
\hline & & & $\begin{array}{l}\text { Durativa } \\
\text { ("por enquanto", } \\
\text { "todo o tempo") }\end{array}$ & - & - \\
\hline
\end{tabular}




\begin{tabular}{|c|c|c|c|c|}
\hline & & $\begin{array}{l}\text { Terminativa } \\
\text { ("Até então", } \\
\text { "até aquele } \\
\text { ponto") }\end{array}$ & - & - \\
\hline & & Pontual & Quando & 09 \\
\hline & Simples & Seguinte & Depois & 03 \\
\hline & interna & Simultâneo & Agora & 04 \\
\hline & & $\begin{array}{l}\text { Anterior } \\
\text { ("até agora") }\end{array}$ & - & - \\
\hline & & Conclusiva & $\begin{array}{l}\text { Dessa forma, } \\
\text { Dessa maneira }\end{array}$ & 02 \\
\hline Modo & Comparação & Positiva & Assim como & 01 \\
\hline & & Negativa & Enquanto & 03 \\
\hline & $\begin{array}{l}\text { Significado } \\
\text { (“assim”) }\end{array}$ & & - & - \\
\hline $\begin{array}{l}\text { Condicional- } \\
\text { causal }\end{array}$ & Geral & & $\begin{array}{l}\text { Pois, porque, uma } \\
\text { vez que, portanto, } \\
\text { então, como }\end{array}$ & 09 \\
\hline & & Resultado & Conseqüentemente & 01 \\
\hline & & Razão & Por isso & 02 \\
\hline & & Propositiva & Para & 23 \\
\hline & & $\begin{array}{l}\text { Condicional } \\
\text { positiva }\end{array}$ & $\mathrm{Se}$ & 09 \\
\hline & & $\begin{array}{l}\text { Condicional } \\
\text { negativa }\end{array}$ & Senão & 01 \\
\hline & & Concessiva & \begin{tabular}{|lr} 
Apesar & $d e$, \\
embora, & mesmo \\
que & \\
\end{tabular} & 03 \\
\hline & & & Total & 99 \\
\hline
\end{tabular}

Como pode ser visualizado, as conjunções de intensidade espaço-temporal especificativa são predominantes, 24 ocorrências, seguidas pelas conjunções de intensidade condicional causal propositiva, com 23 ocorrências.

\section{Exemplo 9}

...os camundongos foram então infectados pela bactéria Listeria monocytogenes. Após três dias, eles apresentaram aumento de 1.000 vezes na contagem de bactérias... (VERJOVSKY, 2006).

\section{Exemplo 10}

Uma pesquisa realizada por pesquisadores da Fundação Oswaldo Cruz (Fiocruz), em parceria com a Universidade Estadual de Santa Cruz (Uesc), na Bahia, analisou mais de três mil seqüências genéticas do vírus da dengue para compreender as mutações sofridas pelo RNA viral (WALTZ, 2008).

\section{Exemplo 11}

"Por ser portuária, a cidade é porta de entrada para outros subtipos do vírus e, como a população de lá toma os remédios há mais tempo, era possível encontrar ali resistências aos medicamentos", diz Ricardo Diaz, infectologista da UNIFESP e um dos coordenadores do estudo. (COELHO, 2001) 
No exemplo 9, há o emprego de uma conjunção de intensidade espaço-temporal específica, no exemplo 10, há o uso de uma conjunção de intensidade condicional causal propositiva. Por fim, no exemplo 11, há o emprego da conjunção "como" sinalizando uma relação de causa.

\subsection{Análise qualitativa}

Todo autor ao produzir um texto espera ser compreendido e aceito, assim durante a produção do texto ele prediz o que o seu leitor sabe do assunto (HYLAND, 2007, p. 267). O autor, portanto, baseado no conhecimento que tem sobre seus leitores, coordena seu discurso para atingir seus objetivos com o texto, fazendo escolhas retóricas que servem para negociar significado de forma mais precisa com seus leitores (idem: ibidem).

A busca pela aceitabilidade e compreensão do texto pode explicar o grande número de ocorrência de conjunções de extensão aditivas positivas, que têm como função complementar a informação que precede, adicionando uma idéia e/ou informação nova, função também das relações de elaboração apositiva expositiva, explicitadas na grande maioria das vezes por símbolos gráficos, as quais são empregadas para caracterizar a informação que precede, clarificando seu significado e refinando a explicação.

A adição de informações, comentários, reformulações e clarificações expressas por relações lógico-semânticas de extensão aditivas e de elaboração apositivas expositiva, são freqüentemente introduzidas nos textos de PC em português pela polifonia, que é iterativa nesses textos, i.e, é empregada ao longo de todo o texto, quando o jornalista necessita especificar ou clarificar alguma informação ou termo para tornar o texto acessível aos leitores. Como os textos de PC em português são escritos por jornalistas (revista eletrônica Ciência Hoje On-Line) e não especialistas no assunto reportado, o jornalista freqüentemente recorre à autoridade, nesse caso, o pesquisador, para elaborar, clarificar, especificar e/ou exemplificar alguma informação e/ou termo, conforme exemplo de um texto do corpus:

Exemplo 12

1 Embora assuma que não se pode generalizar os resultados obtidos para a 2população de fumantes como um todo, a psicóloga acredita que o estudo 3pode ajudar a aprimorar o atendimento aos fumantes. "Os profissionais que 4 atuam em programas de tratamento devem levar em conta os aspectos 5psicológicos do paciente", explica. "Além da costumeira abordagem no 6sentido de alertar para as doenças relacionadas ao fumo, o profissional 7 poderia, por exemplo, trabalhar questões relacionadas à auto-estima e à 8importância do cuidado consigo mesmo." (CHAGAS, 2004)

O Exemplo 12 ilustra o fenômeno da polifonia. Há referência a processos mentais ("assuma"-linha 1, “acredita"-linha 2) em que o Experienciador (a pesquisadora = psicóloga) dos fenômenos é outra pessoa que não o jornalista-narrador, caracterizando, assim, o emprego de polifonia pelo discurso indireto. Aparece ainda o dizer dessa outra pessoa em discurso direto entre aspas.

Desse modo, evidencia-se que as relações de elaboração (por exemplificação-linha 7) e extensão (por adição-linha 5 e 7, e concessão-linha 1) acontecem freqüentemente pela voz do próprio pesquisador.

Segundo Hyland (2005, p. 96), as conjunções nos textos de popularização da ciência focalizam o comportamento externo do fenômeno e funcionam para tornar o mundo real claro para a audiência não-especializada, i.e, são empregadas para fazer conexões proposicionais ao invés de conexões discursivas, contribuindo para o entendimento das relações entre a informação e a realidade. O jornalista, no caso dos textos de PC, controla e processa as informações no texto, adaptando seu discurso ao contexto da audiência. 
Esse fato já havia sido constatado por Pagano (1998), quando é apontado que o termo popularização "traduz-se na incorporação crescente de elementos narrativos à medida que o texto é reescrito para uma audiência mais leiga e geral" (p. 57).

\section{CONSIDERAÇÕES FINAIS}

A análise dos textos indicou um grande número de ocorrências de relações lógicosemânticas de extensão aditivas positivas - sinalizadas pelo emprego de conjunções - e relações de elaboração apositivas expositivas - sinalizadas pelo emprego de símbolos gráficos. A ocorrência dessas relações lógico-semânticas mostra o engajamento do jornalista em acrescentar informações e proporcionar uma facilitação do conteúdo do texto.

Essa atitude do jornalista também é verificada nas freqüentes reformulações, comentários e especificações empregadas para esclarecer algum termo e/ou idéia. Na reescritura do conhecimento científico, tanto a reformulação por meio de informações explicitadas por símbolos gráficos quanto as exemplificações, marcadas pelo emprego de conjunções, são maneiras comuns dos autores tornarem suas idéias acessíveis.

As reformulações de termos e/ou idéias e o acréscimo de informações são recorrente nos textos de PC em português, o que indica que o jornalista procura alcançar determinados significados e efeitos retóricos (HYLAND, 2007, p. 267), preenchendo possíveis lacunas entre o conhecimento especializado e o conhecimento não especializado. Para realizar as reformulações o jornalista, muitas vezes, apela para a autoridade, ou seja, traz a voz do próprio pesquisador para o texto.

Hyland (2005, p.97) aponta que as notícias de PC adotam um estilo de relatar muito próximo do jornalismo popular, empregando freqüentemente a polifonia na forma usual do discurso direto com processos verbais.

Por fim, reformulações e especificações (marcadas por relações de elaboração apositiva expositiva e de extensão aditivas positivas) por meio de paráfrases, exemplificações, comentários e acréscimos de informações, muitas vezes, em co-ocorrência com a polifonia, têm a função de representar as várias perspectivas de diferentes atores sociais sobre a descoberta científica relatada, as quais são apresentadas no texto como forma de promover o debate sobre a ciência e, ao mesmo tempo, diminuir a distância entre o âmbito do conhecimento científico e o do conhecimento não especializado.

\section{REFERÊNCIAS BIBLIOGRÁFICA}

CASAMIGLIA, Helena; VAN DIKJ, Teun. Popularization discourse and knowledge about the genome. Discourse \& Society. London: Sage publications, v. 15, n.4, 2004, p. 369-389.

CHAGAS, Catarina. Estudo relaciona tabagismo com personalidade de universitários. Ciência Hoje On-line, Rio de Janeiro, jul.2004. Disponível em: < http://cienciahoje.uol.com.br/controlPanel/materia/view/2980>. Acesso em: 1o jun. 2008.

COELHO, Sarita. HIV mutante e mais resistente. Ciência Hoje On-Line, Rio de Janeiro, nov. 2001. Disponível em:

<http://cienciahoje.uol.com.br/controlPanel/materia/view/3084 >. Acesso em: 1o de nov. 2008.

COSENDEY, Leonardo. Aspirina pode combater mal de Chagas. Ciência Hoje On-line, Rio de Janeiro, jun. $2008 . \quad$ Disponível em:

< http://cienciahoje.uol.com.br/controlPanel/materia/view/3130>. Acesso em: 1ํ jul. 2008.

CUNHA, Maria Ângela; OLIVEIRA, Mariângela Rios; MARTELOTTA, Mário Eduardo. (Orgs.). Lingüística funcional teoria e prática, Rio de Janeiro: Faperg, 2003.

FAIRCLOUGH, Norman. Discurso e mudança social. Coord. trad., revisão e pref. à ed. bras. de Izabel Magalhães. Brasília: Editora Universidade de Brasília, 2001.

Analysing discourse: textual analysis for social research. London/New York: Routledge, 2003. 
HALLIDAY, Michael A.K.; An Introduction to functional grammar. Revised by Christian Matthiessen. 3d ed. London: Arnold, 2004.

; HASAN, Ruqaiya. Cohesion in english, London: Longman, 1976.

HYLAND, Ken. Metadiscourse: exploring interaction in writing. London: Continuum, 2005.

Applying a gloss: exemplifying and reformulating in academic discourse. Applied Linguistics, London: Oxford University Press, v. 28, n.2, 2007, p. 266-285.

MARQUES, Fernanda. Anomalia genética explica abortos espontâneos. Ciência Hoje OnLine, Rio de Janeiro, mai. $2002 . \quad$ Disponível em: < http://cienciahoje.uol.com.br/controlPanel/materia/view/3068>Acesso em: 10 jun. 2008

MOEHLECKE, Renata. Parasita transfere seu DNA para hospedeiro. Ciência Hoje On-Line, Rio de Janeiro, jul. 2004. Disponível em: <http://cienciahoje.uol.com.br/controlPanel/materia/view/2979 >. Acesso em: 1o de jun. 2008.

MUELLER, Susana Pinheiro Machado. Popularização do conhecimento científico. In: DataGramaZero - Revista de Ciência da Informação, v.3, n.2, 2002, p. 01-11.

XXXXX. O status da linguagem em publicações online de divulgação científica. Trabalho apresentado na Semana Acadêmica de Letras XXXX: A construção da identidade e da brasilidade do sujeito de letras. XXXX: XXX, 2007.

NEVES, Maria Helena de Moura. A gramática funcional, São Paulo: Martins Fontes, 2004.

PAGANO, Adriana. Genes, ovelhas e discos compactos: alguns aspectos das reescritas de descobertas científicas. In: MACHADO, Ida Lúcia. CRUZ, Amadeu Roseli, Dylia LYSARDO-DIAS.

Teorias e práticas discursivas. Estudos em análise do discurso. Belo Horizonte: UFMG, 1998, p. 55-72.

XXXXXXX. Organização retórica e uso de aposto em artigos de popularização da ciência. Trabalho apresentado no 56ํㅡㄹ Seminário do GEL - Grupo de Estudos Lingüísticos. São José do Rio Preto, SP: UNIP - Universidade Paulista e UNESP - Universidade Estadual de São Paulo, 2008.

VERJOVSKY, Marina. Armadilha imunológica. Ciência Hoje On-Line, Rio de janeiro, out. 2006. Disponível em: <http://cienciahoje.uol.com.br/controlPanel/materia/view/61198>. Acesso em: 20 mai. 2008.

WALTZ, Igor. Insulina no combate a ferimentos. Ciência Hoje On-Line, Rio de Janeiro, fev. 2008. Disponível em: <http://cienciahoje.uol.com.br/controlPanel/materia/view/61198>. Acesso em: 10 jun. 2008.

. Estudo mapeia mutações do vírus da dengue. Ciência Hoje On-Line, fev. 2008. Disponível em: < http://cienciahoje.uol.com.br/112979>. Acesso em: 1o jun. 2008. 